\title{
DOCUMENTOS
}

\section{MIGUEL CUSTODIO DURÁN}

\section{Mina RAMÍREZ MONTES}

"Alarife mayor de esta ciudad: maestro en el arte de arquitectura civil y política; ingeniero en la arquitectura militar; medidor de aguas y tierras y valuador de ellas; veedor en el arte de arquitectura..."1

La frase anterior sintetiza los valores de un artífice novohispano, cuyas realizaciones en el mundo artístico están cada día más definidas, gracias a la documentación que se ha venido recopilando y que cubre casi la totalidad de su vida activa. Heinrich Berlin, gran estudioso del arte mexicano, localizó una declaración de Miguel Custodio Durán (1742), en la que afirmaba ser el autor de las iglesias de los hospitales de San Lázaro y de San Juan de Dios de la Ciudad de México, del santuario de Chalma y de los templos de Atitalaquia y Real del Monte. ${ }^{2}$

A raíz de esta declaración y observando los elementos que tienen en común las iglesias de San Juan de Dios y San Lázarọ, se pudieron reconocer ciertas características de su estilo en cuanto a la ornamentación de sus fachadas, específicamente en las estrías onduladas que aparecen en las pilastras de una y en las columnas de la otra, así como el ondulamiento de las cornisas y de los pináculos, los cuales se convirtieron en eternas llamas ardientes, artificios del barroco, tal vez originales, tal vez producto de aires andaluces, de arquitectos como Diego de la Sierra o Lorenzo de Figueroa.

Tal característica, que hasta ahora conocemos como la principal en las

\footnotetext{
${ }^{1}$ González Franco, Glorinela, et al Catálogo de Artistas y Artesanos, México, Instituto Nacional de Antropología e Historia, 1986, p. 34. Apud. Archivo General de la Nación, Bienes Nacionales, Leg. 389, exp. 3.

2 Berlin, H., "Three Master architects in New Spain", The Hispanic American Historical review, v. XXVII, No 2, may 1947, p. 379 Apud. A.G.N , Desagize, v. 11
} 
obras de Custodio Durán, dio pie, a Gonzalo Obregón para atribuirle la autoría de la capilla de la Inmaculada Concepción en la iglesia de Regina ${ }^{3}$, obra bendecida el 15 de noviembre de 1733 , cuya portada tiene un enorme parecido con la lateral de San Lázaro, además de que ambas fueron construidas gracias a la liberalidad de los Medina Picazo, que también contribuyeron económicamente en el Colegio jesuita de Tepotzotlán y donde actuaron como arquitectos, miembros de la familia Durán. ${ }^{4}$

A veces, el encontrar ciertas características peculiares de un artífice, propicia el que los historiadores del arte neguemos a esos mismos artistas la oportunidad de manifestarse de manera distinta en otras obras. Este caso es uno de ellos, pues, en lo personal yo hubiera querido encontrar en la iglesia de Atitalaquia esa variedad de expresiones ondulantes, sin embargo, son escasas, tan sólo las cornisas recuerdan ese movimiento, en la portada parece triunfar la línea recta sobre la curva, son sus elementos tan distintos a los usados por Durán, que me hicieron reflexionar sobre la evolución de las formas que fue creando y adoptando este artista que no tuvo por norma el anquilosamiento.

Partiendo de las características más comunes del estilo de Custodio Durán, Luis Brozon cree posible que también fuera el diseñador o maestro de obras de la iglesia parroquial de Zumpango de la Laguna ${ }^{5}$, obra de la primera mitad del siglo XVIII, cuya fachada presenta el mismo rehundimiento de la iglesia de San Juan de Dios, ambas tienen dos cuerpos rematados por una venera inscrita en un medio punto y en el primer registro presentan dos niveles de nichos entre pilastras onduladas. Las calles centrales sólo se diferencian por la inversión de sus elementos, en Zumpango el nicho central está en el remate y el óculo sobre la puerta de entrada y en San Juan de Dios sucede lo contrario.

El principal objetivo de este artículo es dar a conocer ciertos documentos familiares de Miguel Custodio: el recibo de la dote de su esposa y el poder para testar que otorgó a ella misma, y uno de carácter técnico: el proyecto y la descripción de la capilla del Carmen de la iglesia de San Sebastián de México, obra que realizó al reconstruir este templo, estrenado con gran ceremonia el 14 de octubre de $1742 .{ }^{6}$ Otro objetivo fue el

\footnotetext{
${ }^{3}$ Obregon, Gonzalo, La capilla de los Medina Picazo en la iglesia de Regina Coeli, México, Instituto Nacional de Antropología e Historia, 1971, pp. 17 y 27.

${ }^{4}$ Tovar de Teresa, Guillermo, "Quien fue el creador de Tepotzotlán", La Jornada semanal, México, D. F., 28 de agosto de 1988, pp. 1, 4-5.

${ }^{5}$ Brozon Mac Donald, Luis, "Dos portadas 'abocinadas' en el valle de México", Boletín de Monumentos Historicos, No. 3, Instituto Nacional de Antropología e Historia, p. 16

${ }^{6}$ Obras de fray Andrés de San Miguel, Introducción, notas y versión paleográfica de Eduardo Báez Macías, México, UNAM, Instituto de Investigaciones Estéticas, 1969, p. 32
} 
hacer una cronología de sus obras documentadas, la lista se inicia en 1696 y se concluye cincuenta años después. Los datos son escuetos y la mayoría de las obras ya no existen, sin embargo la aportación será útil para valorar su trabajo.

Miguel Custodio Durán nació en la Ciudad de México hacia el año 1680. Fue hijo del también arquitecto José Durán, natural de Tetepango, y de Beatriz Gómez de la Fuente y Ayala. Nieto por línea paterna de Fernando Durán y de Luisa Sarmiento (?) de Mendoza Segundo de siete hermanos: Josefa, Sebastián, Gregorio, María, Fernando y Francisco. En 1732 se casó con Úrsula Téllez Girón, probablemente hermana del arquitecto Antonio de los mismos apellidos, de quien no tuvo descendencia. Fue tío del arquitecto Ildefonso de Iniesta Bejarano, hijo de su hermana María. ${ }^{7}$ Otorgó poder para testar a su esposa en el año de 1746, cuando se encontraba muy enfermo, es posible que muriera este mismo año.

\section{CRONOLOGÍA DE SU VIDA Y DE SU OBRA EN LA CIUDAD DE MÉXICO Y EN EL ACTUAL ESTADO DE HIDALGO}

1680 Probable año de nacimiento de Miguel Custodio, puesto que su padre declaró el 5 de marzo de 1707, que su hijo varón mayor tenía entonces más de veinticinco años."

1696 Se inicia en el trabajo, tal vez como oficial al lado de su padre. ${ }^{9}$

1707 Dirigió la conducción del agua a la hacienda de los Dolores por encargo de los padres de la Compañía de Jesús de Tepotzotlán, ellos la realizaron y Durán regresó siete años después a concluirla. ${ }^{10}$

1712 Obtuvo carta de examen de su arte. ${ }^{11}$

1720 Marzo 5. Contrató la obra de una casa en la calle de Regina, la cual se describe con detalle. ${ }^{12}$

Junio 20. Declaró ser vecino de la Ciudad de México y poseer una

\footnotetext{
${ }^{7}$ En el testamento otorgado por José Durán. Ramírez Montes, Mina, Catálogos de documentos de arte en el Archivo de Notarias de la ciudad de Méxiç, México, UNAM, Instituto de Investigaciones Estéticas, 1990, No. de catálogo 027.

${ }^{8}$ Ibidem.

${ }^{9}$ Declaró en 1742, tener 46 años al servicio de la construcción. A.G. N., Desagüe, v. 11, exp. $62, \mathrm{fs}, 15 \mathrm{v}-16$

${ }^{10}$ A.G. N., Desagüe, v. 11, exp 62, fs. 17-17v.

11 Declaró en 1742, tener 30 años de examinado. A.G.N., Desagüe, v 11, exp. 62, fs 15v-16.

12 Tovar de Teresa, Guillermo, Mexico barroco, México, Secretaría de Asentamientos Humanos y Obras Públicas, 1981 "Apud, Archivo de Notarías de la ciudad de México, Not. Nicolas Varela (691).
} 
casa nueva, entresolada, de cal, arena y piedra, que él había construido, ubicada en la calle del Águila. ${ }^{13}$

Julio 6. Se comprometió a pagar una deuda a Miguel de Gelos. ${ }^{14}$

Julio 10. Se comprometió a pagar cierta deuda a Antonio Fernández de Bársena. ${ }^{15}$

1724 Reconoció el plano para la construcción de la cárcel y la sala de la hacienda en el palacio real. Hizo postura para su contratación. Como veedor del gremio de arquitectos participó en el reconocimiento de la nueva Casa de Moneda. ${ }^{16}$

1725 Recibió el pago correspondiente a la inspección realizada en ciertas casas antiguas del convento de Jesús María que pretendía comprar el Hospital del Amor de Dios. ${ }^{17}$

Inició sus intervenciones en algunas casas propiedad del marquesado del Valle y en la capilla de Santa Efigenia. ${ }^{18}$

1726 Hizo postura para la construcción de unas viviendas, situadas encima de las caballerizas hacia el parque del real palacio. ${ }^{19}$

Noviembre 27. Recibe como aprendiz de cantero a Juan Josef Altamirano, por tiempo de cuatro años. ${ }^{20}$

1728 Julio 13. Contrató la construcción de una casa en la calzada de San Antonio abad, propiedad de Laureano Gregorio. ${ }^{21}$

1729 Tasó una celda en el convento de la Concepción." ${ }^{22}$

1732 Septiembre 13. Otorgó escritura de la dote de su futura esposa Úrsula Téllez Girón, la cual al no aportar bienes al matrimonio más que su honra y estirpe, él le dio cierta cantidad de su haber y al mismo tiempo la recibió, obligándose a no incluirla en deudas, crímenes, ni excesos y en caso de disolución del vínculo matrimonial se los devolverían a ella. Se deja entrever que también lo hizo con la finalidad de hacer constar que su caudal provenía de su trabajo y que no pertenecía a la herencia de su padre, de tal

13 A.N.cd.M., Nol Nicolás Varela (691), año 1720.

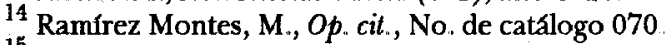

15 Ibidem, No. de catálogo 071.

16 Varios, Palacio Nacional México [s.p. i.] [1976].

${ }_{17}$ Comunicacion oral de Nuria Salazar, a quien le agradezco.

18 Báez Macías, Eduardo, El edificio del Hospital de Jesuis, historia y documentos sobre su construcción, México, UNAM, Instituto de Investigaciones Estéticas, 1982, p. 56.

${ }^{19}$ Varios, Op. cit.

${ }^{20}$ Ramírez Montes, M., Op. cit., No. de catálogo 140.

21 Ibidem, No. de catálogo 157.

${ }_{22}$ González Franco, Glorinela, "Notas para una guía de artistas y artesanos de la Nueva España III", Boletín de Monumentos Históricos, México, Instituto Nacional de Antropología e Historia, No 5, 1981, p. 89. Apud. A.G. N., Bienes Nacionales. 
DOI: http://dx.doi.org/10.22201/iie.18703062e.1990.61.1559

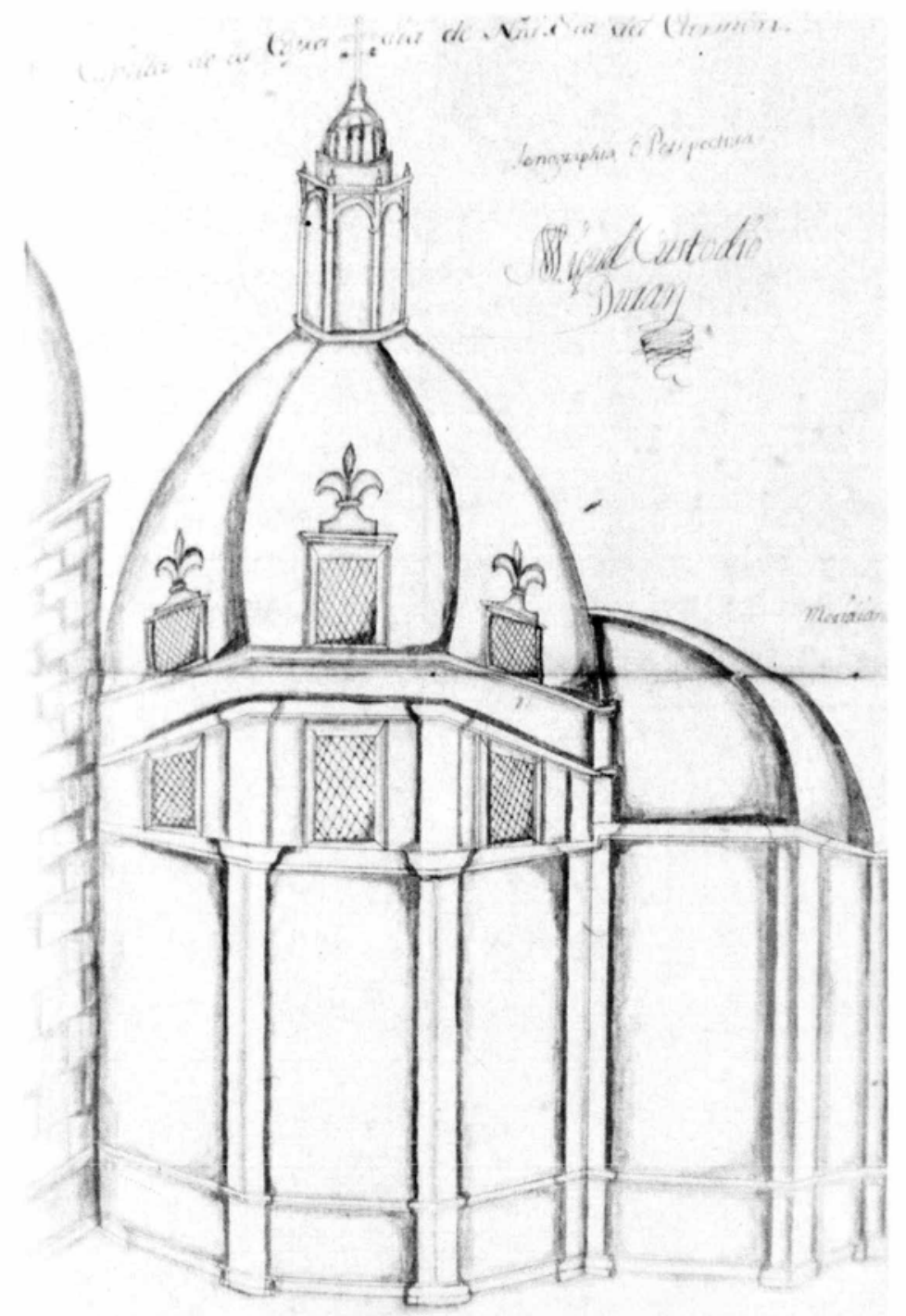

1. Alzado del exterior de la capilla de Nuestra Señora del Carmen en la iglesia de San Sebastián. Obra de Miguel Custodio Durán.

Ciudad de México. 
DOI: http://dx.doi.org/10.22201/iie.18703062e.1990.61.1559

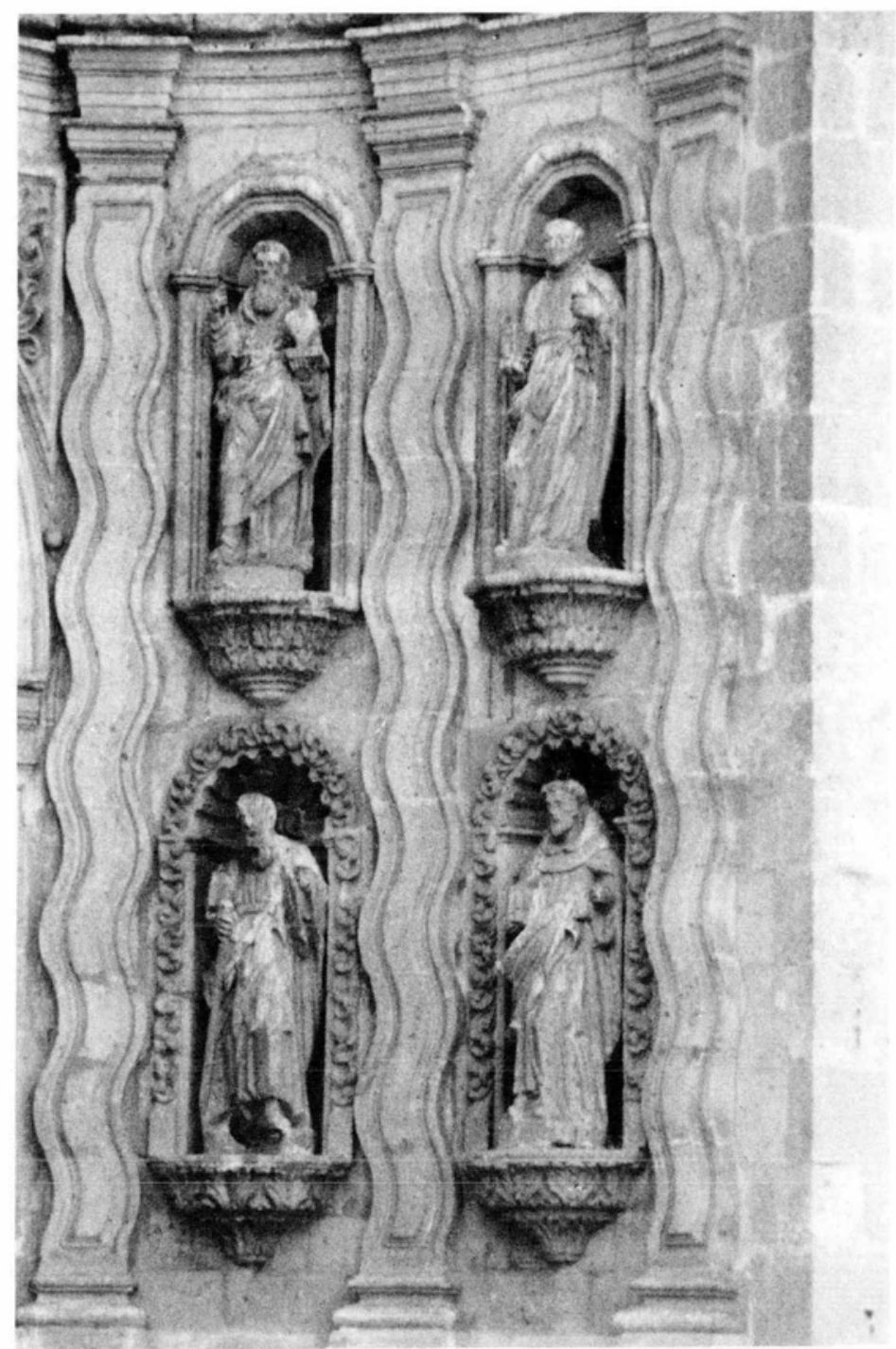

2. Fachada de la iglesia de San Juan de Dios. Obra de Miguel Custodio Durán.

Ciudad de México. 
DOI: http://dx.doi.org/10.22201/iie.18703062e.1990.61.1559

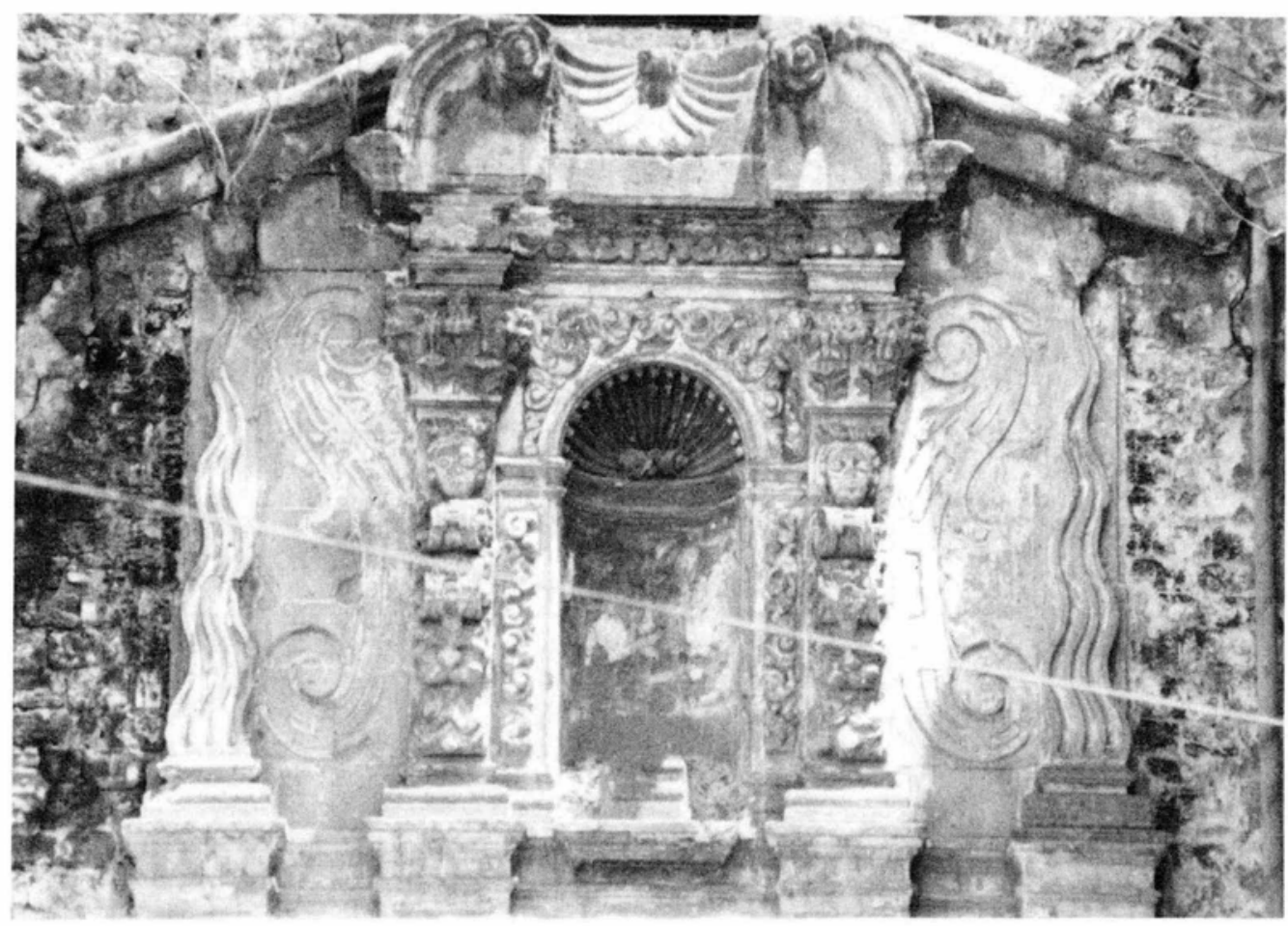

3. Portada lateral de la iglesia de San Lázaro. Obra de Miguel Custodio Durán. Ciudad de México. 
DOI: http://dx.doi.org/10.22201/iie.18703062e.1990.61.1559

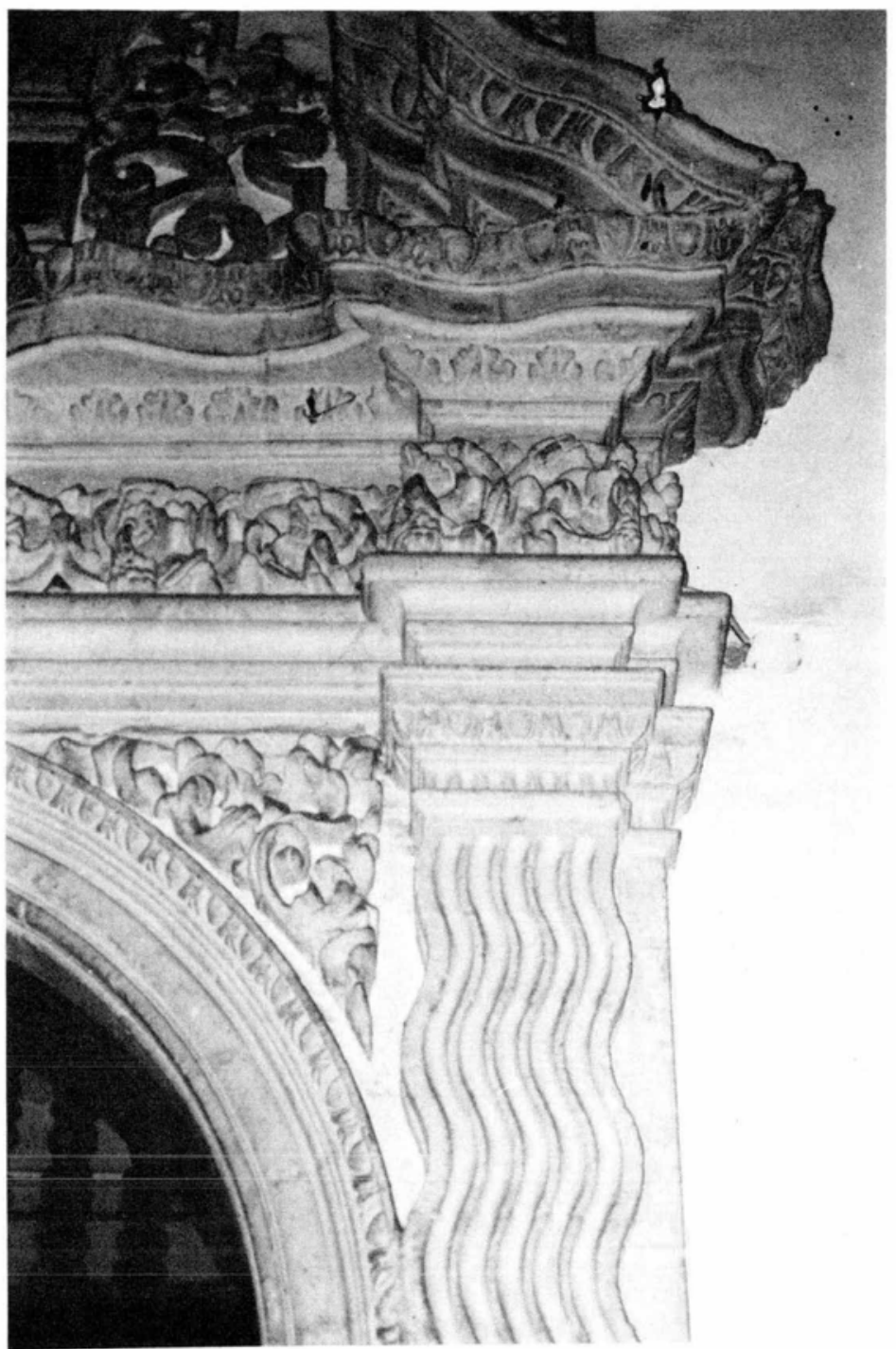

4. Portada de la capilla Medina Picazo, Iglesia de Regina. Obra atribuida a Miguel Custodio Durán. Ciudad de México. 
manera que si moría antes que su mujer, a ella no se le quitase (ver Documento No. 1).

Septiembre. Junto con Antonio Álvarez y José Eduardo de Herrera inspeccionó los trabajos que se estaban realizando en la Casa de Moneda. Luego que declararon los artífices, el virrey ordenó que Herrera hiciera una planta "según arte la más hermosa, fuerte, estable y bien distribuida que sea posible..." una vez realizada la planta y montea, los arquitectos Pedro de Arrieta, Miguel Custodio Durán, Antonio Álvarez y Miguel de Rivera la inspeccionaran, al ver que estaba correcta se construyó de esa manera. ${ }^{23}$

Noviembre 7. Junto con los arquitectos José Eduardo de Herrera y Antonio Álvarez, presentó una declaración sobre los defectos en la construcción de la nueva Casa de Moneda.. ${ }^{24}$

1733 Enero 26. Efectuó la valuación de unas casas. En este año fue veedor de su gremio. ${ }^{25}$

Febrero 21. Junto con los arquitectos Pedro de Arrieta, Antonio Álvarez, Miguel José de Rivera, Nicolás de Meza, Manuel Álvarez y José Eduardo de Herrera, se comprometió a examinar a los aspirantes a formar parte del gremio de la construcción, con la finalidad de evitar problemas en los edificios de esta ciudad. ${ }^{26}$

Julio 15. Contrató la reparación de una casa en la calle de la Palma, propiedad de Juan Fernández de Otaz. Se describe con detalle. ${ }^{27}$

Noviembre 15. Dedicación de la capilla de la Inmaculada Concepción en la iglesia de Regina, ${ }^{28}$ obra atribuida a Miguel Custodio.

1734 Junio 10. Actúa como fiador del arquitecto José Eduardo de Herrera, quien se comprometió a realizar una casa de la Congregación de San Pedro. ${ }^{29}$

Julio 7. Contrató la reparación de unas casas, propiedad del cura Juan de Dios Lozano. ${ }^{30}$

${ }^{23}$ Marco Dorta, Enrique, Estudios y documentos, p. 31 . En la p. 113 está el informe completo de los arquitectos mencionados.

${ }^{24}$ Varios. Op cit., pp. 236-238. Apud., A. G.N., Casa de Moneda, v. 213.

${ }^{25}$ Ramírez Montes, Mina, Op. cit., No. de catálogo 195

26 Véase el documento compieto en: Tovar de Teresa, Guillermo, "Del barroco salomónico al barroco estípite. Consideraciones sobre un documento relativo al gremio de los arquitectos de la ciudad de México", Cuadernos de Arte Colonial, Madrid, Museo de América, Octubre de 1987, No. 3, pp. 124-127., Apud., A.N.cd. M. Not. Felipe Muñoz de Castro (391), fs. 41-42v.

${ }^{27}$ Bravo Sandoval, Silvia, Catalogos de documentos de arte en el Archivo General de Notarias, México, UNAM, Instituto de Investigaciones Estéticas, 1985, No. de catálogo 204.

${ }_{28}^{28}$ Inscripción en la portada.

${ }_{30}^{29}$ Ramírez Montes, M , Op. cit., No de catálogo 211 .

${ }^{30}$ Ibidem, No. de catálogo 212. 
Septiembre 20. Junto con los arquitectos Pedro de Arrieta, Miguel José de Ribera y José Eduardo de Herrera, reconoció y avaluó la portada principal de la Casa de Moneda. ${ }^{31}$

Octubre 7. Contrató la construcción de una casa en el "puente quebrado". Se describe con detalle. ${ }^{32}$

Octubre 9. Contrató la reedificación de una casa del Colegio de San Andrés. Fue su fiador el arquitecto Manuel Álvarez. ${ }^{33}$

Diciembre 23. Valuó unas casas entresoladas, situadas bajo la puente que llaman de los Gallos, propiedad de José de Torices.. ${ }^{34}$

1735 Marzo 9. Beatriz Gómez de la Fuente, esposa de José Durán y madre de Miguel Custodio otorgó testamento en esta ciudad. ${ }^{35}$

Agosto 16. Tasó una casa ubicada entre la torre del convento de la Encarnación y la Aduana de esta ciudad. Se incluye el recibo que amparaba la cantidad recibida por el maestro Durán, quien realizó los reparos necesarios. ${ }^{36}$

1736 Enero 31. Reconoció y arregló las atarjeas del convento de Jesús María $^{37}$

Marzo 21. Junto con el arquitecto Pedro de Arrieta reconoció las obras del desagüe en Huehuetoca. ${ }^{38}$

Septiembre 7. Tasó una casa en la calle de la Cadena perteneciente al convento de la Encarnación y otorgó memoria de los gastos realizados en ella. ${ }^{39}$

Septiembre 7. Reconoció una casa principal del convento de la Encarnación. ${ }^{40}$

Octubre 26. Reconoció y dio presupuesto de los reparos que necesitaba una casa en la calle de Juan Manuel. ${ }^{41}$

Presentó memoria y razón del mapa de cinco casas principales y tres entresoladas, ubicadas en la calle del Águila, las cuales pretendía comprar el convento de La Concepción. ${ }^{42}$

${ }^{31}$ Varios, Op cit., p. 240 Apud., A.G.N., Casa de Moneda, v. 177.

${ }^{32}$ A. N.cd. M., Not. Francisco de Valdés, año 1734.

${ }_{33}^{33}$ Ramírez Montes, M., Op. cit ., No de catálogo 216.

${ }_{35}^{34}$ Bravo Sandoval, $S_{\text {, }}$ Op. cit , No. de catálogo 215.

35 A.N.cd. M. Not. Felipe Muñoz de Castro (391), año 1735.

${ }^{36}$ López Reyes, José Luis, Cátálogos de documentos de arte en el Archivo General de la Nación:

Ramo Templos y conventos, segunda parte, México, UNAM, Instituto de Investigaciones Estéticas, 1985, No de catálogo 293.

${ }_{38}$ Comunicación oral de Nuria Salazax, a quien agradezco el dató.

${ }_{38}$ A.G.N., Desagüe, v. 11, exp. 57, fs. 14-16.

${ }^{39}$ López Reyes, J. L., Op. cit., No de catálogo 299.

${ }^{40} \mathrm{Ibidem}$, No. de catálogo 299.

41 Ibidem, No de catálogo 300

42 González Franco, G. "Notas para una gứa ...", op cit, , pp. 89-90. 
Valuó un sitio para el convento de San Jerónimo. ${ }^{43}$

Reconoció, junto con José Eduardo de Herrera, una celda en el convento de la Encarnación. ${ }^{44}$

Valuó una celda baja en el convento de San Lorenzo. ${ }^{45}$

1737 Abril 10. Contrató la construcción de una celda en el convento de Jesús María. ${ }^{46}$

Abril 27. Construyó dos casas principales con sus accesorias, frente a la torre vieja del convento de San José de carmelitas descalzas. Se encuentra la memoria de gastos avalada por él. ${ }^{47}$

Septiembre 14. Junto con los arquitectos Pedro de Arrieta, Miguel José de Rivera, José Eduardo de Herrera, Manuel Álvarez y el veedor Francisco Valdés, realizó un plano de la Ciudad de México en el que se demarcaron las normas de evaluación de los edificios por zonas. ${ }^{48}$

Septiembre 6. Plano que por el nombre de su autor lo he relacionado con el artífice en cuestión: planta de una casa en la Cañada de Zamora, Tolcayuca, hoy en el Estado de Hidalgo. Autor: Miguel Durán, vecino del pueblo de Cuautitlán, inteligente en el arte de arquitectura. ${ }^{49}$

1738 Julio 21. Valuó unos sitios y sus construcciones. ${ }^{50}$

Plano de la Casa de la hacienda de San Francisco Apasco en Atitalaquia, Hgo. Autor: Miguel Durán, albañil y arquitecto. ${ }^{51}$

1739 Trabajó en el envigado de la escalera del convento de Jesús María. ${ }^{52}$ Julio 18. Se le extendió nombramiento como maestro de obras del Hospital de Jesús, por muerte del maestro Pedro de Arrieta, permaneció como tal hasta 1745 con el invariable salario de cincuenta pesos anuales. ${ }^{53}$

1740 Fue veedor de su gremio. Actuó como maestro de obras del con-

Ibidem

${ }^{44}$ Ibidem

${ }^{45}$ Ibidem.

46 Salazar, Nuria, El convento de Jesús María de la ciudad de México, historia artística 15771860 , México, Tesis de licenciatura en Historia del Arte, Universidad lóroamericana, 1966 , p. 103

${ }_{47}$ López Reyes, J. L., Op. cit., No de catálogo 302

${ }^{48}$ Ramírez Montes, M., Op. cit., No. de catálogo 229.

${ }_{50}^{49}$ A.G.N., Tierras, v. 397, exp. 3, f. $127.31 \times 37 \mathrm{~cm} \mathrm{97/0947}$

50 Ramírez Montes, M., Op. cit ,, No. de catálogo 234.

51 A.G.N., Tierras, v. 2045, exp. 8, cuad. 2, f. 42, 31-37 cm 977/1455.

${ }^{52}$ Salazar, Nuria., Op. cit., p 87.

${ }^{53}$ Báez Macías, E., Op. cit , pp. 54 y 56 
vento de Jesús María, tal vez por este año y el siguiente, ya que para 1742 lo fue el arquitecto José Antonio de Roa. ${ }^{54}$

Agosto 31. Junto con los arquitectos Luis Díez Navarro y Manuel Álvarez, Durán examinó a Lorenzo Rodríguez, le pidió que delinease "una bóveda con diferentes circunstancias, partes y divisiones de ella y explicado sus razones, divisiones y cuenta... ${ }^{55}$

1741 Julio 11. Realizó el plano de la capilla de la cofradía del Escapulario de Nuestra Señora del Carmen en la iglesia de San Sebastián de los carmelitas. Las obras de la capilla corrían paralelas con las de renovación de la iglesia a cargo también de Custodio Durán (ver Documento No. 2).

Continúa trabajando en las obras de la iglesia de San Sebastián ${ }^{56}$ Lorenzo Rodríguez lo atacó diciendo que cometió un error en la altura de la cúpula. Durán se excusó al aclarar que él diseñó y los religiosos por ahorrar costos construyeron, recurriendo a él más tarde para corregir los errores. ${ }^{57}$

1742 Trabajó en el palacio real de Huhuetoca, obra que anteriormente estuvo a cargo del arquitecto Lorenzo Rodríguez, por lo que entre ellos se entabló un pleito. Durán dijo de Rodríguez: "ni es maestro examinado ni aprobado para hacer postura a ésta ni a ninguna obra pública" y agregó que él mismo lo reprobó en el examen, a lo que Rodríguez contestó: "la ciencia arquitectónica la traje muy amplia desde los reinos de España... el mismo Durán firmó y juró mi carta de examen en esta ciudad..." a lo que Miguel Custodio aclaró que gracias a la intervención del corregidor se le había expedido dicha carta, mas con la condición de que durante seis meses se ejercitara con algún maestro y hasta la fecha no había cumplido.

Baltasar de Vidaurre, abogado de Durán, se expresó en estos términos de su cliente: "ser el único, el día de hoy en este reino a más que lo hace constar el ejercicio de cuarenta y seis años y treinta de maestro examinado, criado en este terreno con original conocimiento de sus pisos, corrientes y situaciones, que es el primer fundamento para que salga un operario arquitecto con toda perfección $n^{n} .{ }^{58}$

\footnotetext{
${ }_{55}^{54}$ Salazar, N., Op. cit., p. 88 .

${ }^{55}$ Berlin, H., Op cit., 1947. Apud., A.G.N., Desagüe, v. 11, exp 62

${ }^{56}$ A.N.cd.M., Not. Juan Francisco Benitez de Trigueros, fs. 238- 239.

57 A.G.N., Desagüe, v. 11, exp. 62, f. 10.

58 A.G.N., Desagize., v. 11, exp. 62 , fs. $15 \mathrm{v}-16$
} 
La querella refleja la inconformidad de un criollo conciente de su nacionalidad que veía en el español al prepotente, sólo por haber nacido en la Península, y al usurpador de sus fuentes de trabajo.

Septiembre 19. Se le adjudicó la obra del palacio real de Huehuetoca, al dictarse sentencia a su favor. ${ }^{59}$

Realizó reparaciones en las bóvedas de la iglesia del Hospital de Jesús. ${ }^{60}$

1743 Dictaminó, junto con el arquitecto Manuel Álvarez, el valor de propiedades civiles en el barrio de San Salvador Xiquitingo. ${ }^{61}$

Noviembre 16. Mapa de la hacienda de San Ildefonso, río de San Pedro Atzcapotzaltongo, Cuautitlán, Edo. Méx. Autores: Pedro Alarcón y Miguel Durán. Se encuentra el dictamen, firmado por ambos, la rúbrica de Miguel Durán es muy elaborada, distinta a las que se conocen de él, aunque hay que tener en cuenta que en esta época las personas no siempre firmaban igual. ${ }^{62}$

1744 Según Gonzalo Obregón, en este año murió Miguel Custodio, ahora sabemos que debió ser en o después de 1746 , año en que testó. ${ }^{63}$

1745 Valuó unas casas del convento de Santo Domingo, sitas frente a éste. ${ }^{64}$

Dictaminó el valor de unas casas en la calle de los Donceles. ${ }^{65}$

Figuro en la Ciudad de México como maestro de las artes de arquitectura política y militar e ingeniero en lo militar, agrimensor y apreciador de aguas. ${ }^{66}$

1746 Abril 2. Por encontrarse muy enfermo, otorgó poder para testar a su esposa Ursula Téllez Girón (Ver Documento No. 3).

Abril 26. Los maestros de arquitectura Miguel Custodio Durán y Lorenzo Rodríguez, veedores del gremio; Miguel Espinosa de los Monteros; José Eduardo de Herrera; Manuel Ávarez; José de Roa, Bernardino de Orduña, José Antonio González e Ildefonso de Iniesta Bejarano, presentaron algunas reformas y adiciones a las Ordenanzas de Albañiles que existían. ${ }^{67}$

${ }^{59} \mathrm{Ibidem}$, fs. $18-19 \mathrm{v}$.

${ }^{60}$ Báez Macías, E., Op cit., p. 56.

${ }^{61}$ González Franco, G., Notas para una guta..., pp. 89-90.

${ }_{62}$ A.G.N., Tierras, v. 2045, exp 1, f. 326, 31x41, 977/0892.

63 Obregon, G., Op. cit., p. 27.

${ }_{64}^{64}$ González Franco, G., Notas para una guía..., pp. 89-90.

${ }^{65} \mathrm{Ibidem}$

${ }^{66}$ Varios, Op. cit., p. 303.

${ }^{67}$ Fernández, Martha, Arquitectura y gobierno virreinal, los maestros mayores de la ciudad de México, siglo XVII, México, UNAM, Instituto de Investigaciones Estéticas, 1985, pp. 293-295. Apud Archivo del ex-Ayuntamiento de la ciudad de México, Ordenanzas, Leg. 14, exp. 2983. 


\section{DOCUMENTO No. 1}

\section{ESCRITURA DE DOTE}

Cd de México, 13 de septiembre de 1732

En el nombre de Dios nuestro Señor todopoderoso amén, sea notorio a los que la presente vieren, como yo don Miguel Custodio Durán, vecino de esta ciudad y maestro del arte de arquitectura en ella, hijo legítimo de don Josef Durán de Almendrarejo y doña Beatriz Gómez de la Fuente y Ayala. Digo que por cuanto para honra y servicio de Dios nuestro Señor, estoy tratado de casar a ley y bendición de nuestra santa madre Iglesia con doña Ursula Telles Girón, doncella, vecina de esta corte, hija legítima de don Nicolás Telles Girón, difunto y de doña Micaela de Morales.

Yal tiempo y cuando se trató y concertó dicho matrimonio, se me representó por la dicha doña Micaela no tener otro caudal que su virtud y nobleza, la que es notoria por su conocida estirpe y recogimiento en que siempre se ha conservado, cuya dote era solamente la que tenía dicha doña Ursula y la que sólo me prometía, como la más estimativa entre personas de punto y honra, cuya desnudez y verdad atendiendo, y respecto a que sólo el fin particular que me mueve es el servicio de Dios, en atención a que dicho matrimonio ha de tener efecto (mediante su voluntad) el día del glorioso arcángel señor San Miguel, que se contarán veintinueve del corriente mes y año, he deliberado de mi propio caudal, que es al presente el de cuatro mil y seiscientos pesos, adquiridos a mi propio trabajo y sin que en ellos tenga persona alguna derecho que representar ni vínculo alguno a que se hallen afectos, otorgar carta de dote de la cantidad de un mil pesos a la dicha doña Ursula Telles Girón, por su virginidad y limpieza, o por via de donación, arras o lo que hubiere lugar en derecho, el que atendiendo declaro que aunque la dicha doña Beatriz, mi madre, es viva, y la tengo y siempre la he tenido en mi compañia, atendiéndola y socorriéndola con todo lo necesario, para que ésta en caso de fallecer sin sucesión, no sea perjudicada en su herencia y pueda reasumir el derecho que la asiste, sin perjuicio de la dicha mi esposa, que ha de ser, quiero lo verifique en los tres mil seiscientos pesos que quedan de mi caudal, porque aunque éste lo regulo en cuatro mil seiscientos pesos, no contando el auge de mis dependencias, que con ellas pueden ser, quinto de mis bienes, los expresados un mil pesos que para dicho efecto tengo destinados.

Lo cual reduciéndolo a instrumento público, por la presente y en aquella vía y forma que mejor en derecho lugar haya, otorgo que aplico y doy en dote, de mi propio caudal, a la dicha doña Ursula Telles Girón, los expresado un mil pesos de oro común del quinto de mi caudal, de que le hago gracia y donación puramente, perfecta e irrevocable como contrato entre vivos, en remuneración de su virginidad y limpieza y por vía de arras o más aceptable, propter nupcias y en derecho permitida, de cuya cantidad (a mayor abundamienio) me doy por eniregado a mi voluntad, sobre que renuncio la excepción de pecunia leyes de la entrega, su prueba y demás del caso y me obligo, desde hoy en adelante, a tener en mi poder y por dote y caudal conocido de la dicha mi esposa que ha de ser, los referidos un mil pesos y a no obligarlos a ninguna de mis deudas, crímenes ni excesos, tácita ni expresivamente y cada y cuando que dicho matrimonio fuere disuelto o separado por cualquiera de las causas que el derecho previene, le daré y entregaré a la dicha doña Ursula, o quien representare su derecho, los referidos un mil pesos, sin retenerlos el tiempo que me debe ser concedido, en reales, bien y llanamente sin pleito alguno, y si lo hubiere con las costas y salarios de su cobranza en la forma acostumbrada. 
A cuya observancia y cumplimiento obligo mi persona y bienes, habidos y por haber $y$ con ellos me someto al fuero y jurisdicción de los jueces y justicias de su majestad, de cualesquier partes que sean, en especial a las de esta ciudad, corte y real audiencia de ella, renuncio el mío propio, domicilio y vecindad, ley sit convenerit, las demás de mi favor y defensa con la general del derecho; para que me compelan y apremien como por sentencia pasada en cosa juzgada.

Que es hecha en la ciudad de México, a trece dias del mes de septiembre de mil setecientos treinta y dos años. $Y$ el otorgante, a quien yo el escribano doy fe conozco, asi lo otorgó y firmó siendo testigos; Josef Flores, Antonio Marchena y Bernardino Garnica, vecinos de México.

Miguel Custodio Durán [ríbrica]

Ante mí

Felipe Muñoz de Castro [nibrica]

escribano real

A.N cd de M. Not. Felipe Muñoz de Castro (391), Libro 2588, fs. 385-386 v.

\section{DOGUMEN'TO No. 2}

\section{ALZADO DE LA CAPILLA DEL CARMEN EN LA IGLESIA DE SAN SEBASTIÁN}

Cd, de México, 11 de julio de 1740.

\section{Senografia o Perspectiva}

Razón de la distribución y planta de la capilla que actualmente se está labrando en el convento de Nuestra Señara del Carmen, la cual se compone en su longitud, de veintidós varas que corren de septentrión al mediodía, quedando por esta parte su presbiterio muy capaz, de siete varas de hueco y el cuerpo de dicha capilla se compone de trece varas diametro y en ella quedan cuatro huecos para cuatro altares, fuera del que ha de llevar su presbiterio, el cual ha de quedar descubierto con una bóveda, a modo de concha para su mayor lucimiento y el cuerpo de dicha capilla va en figura ochavada y ésta ha de quedar cubierta con un cimborrio, con su sotabanco y en él han de quedar una orden de ventanas y otra orden de ellas en su media naranja, para que por ellas se comunique bastante luz y si se quisieren ahorrar las ventanas de su sotabanco se pueden dejay en su lugar, por la parte anterior, unos nichos para colocar en ellos algunos santos de la orden, la media naranja llevará su claraboya con su linternilla por donde también se le comunicará bastante luz.

Desde el pavimento de dicha capilla a lo más alto de su media naranja quedará en veintidós varas, que es suficiente elevación con que quedará muy garbosa. Por la parte interior irá adomada con sus arquitrabes, frisos y cornisas para su mayor hermosura, asimismo la arquitectura que le corresponde por lo exterior de ella, todo lo cual tendrá de 
costo, perfectamente acabada, la cantidad de veinte mil pesos, esto es desde sus cimientos hasta su coronación.

$Y$ así lo declaro y para que conste lo firmé en 11 de julio de 1740 años.

Miguel Custodio Durán [ríbrica]

A.N.cd.M., Not Juan Francisco Benitez de Trigueros, año 1741, $f 3$.

\section{DOCUMENTO No. 3}

\section{PODER PARA TESTAR}

Cd. de México, 2 de abril de 1746.

En el nombre de Dias nuestro Señor, trino y uno, todopoderoso amén. Publico y notorio sea a los que el presente vieren, como yo don Miguel Custodio Durán, vecino y originario de esta ciudad de México, y maestro veedor del arte de arquitectura, hijo legítimo de don Josef Durán y de doña Beatriz Gómez, difuntos. Estando enfermo en cama, de la enfermedad que Dios nuestro Señor ha sido servido darme, en mi entero juicio, cumplida memoria y entendimiento natural, creyendo como firmemente creo el altísimo misterio de la Santísima Trinidad, Dios padre, Dios hijo y Dios Espiritu santo, tres personas distintas y un sólo Dios verdadero y todos los demás misterios y sacramentos que tiene cree y confiesa nuestra santa madre Iglesia católica, romana, bajo de cuya fe y creencia declaro haber vivido y protesto vivir y morir, como católico cristiano, eligiendo por mis auxiliares patronos y abogados a la siempre Virgen María madre de Dios y señora nuestra, concebida sin la culpa original en el primer instante de su ser; al glorioso patriarca señor san José, su divino esposo, al ángel de mi guarda y gloriosa virgen santa Catalina de Sena, para que con los demás de mi devoción, pida n y alcancen con nuestro Señor Jesucristo el que mis pecados sean perdonados y mi ánima puesta en carrera de salvación, temiéndome de la muerte $y$ lo incierto de su hora, en cuya presencia digo, que por cuanto la gravedad de mi accidente no me da lugar a poder hacer mi testamento y para que las cosas a él tocantes y al descargo de mi conciencia las tengo tratadas, conferidas y comunicadas con doña Ursula Telles, mi legítima mujer, persona de toda satisfacción y confianza mía, a quien he deliberado darle poder para testar, que es el presente."

Por el cual otorgo que se lo doy y confiero, para que por mi, en mi nombre, después de mi fallecimiento y dentro del término que dispone la Ley treinta y tres de Toro y aunque sea pasado, haga, ordene y otorgue mi testamento con las cláusulas que le tengo comunicadas, que de la suerte que lo hiciere quiero se guarde, cumpla y ejecute por mi última voluntad, y siendo fallecido mi cuerpo, sea sepultado en la iglesia, parte y lugar que pareciere a mi albacea testamentaria fideicomisaria, a cuya disposición lo dejo con lo demás de mi funeral, entierro y mandas forzosas. Declarando como declaro, soy casado y velado, segrin orden de nuestra santa madre Iglesia, con dicha doña Ursula Telles Girón y al tiempo y cuando contraje matrimonio le otorgué el recibo y carta de dote a su favor, a que me remito [Ver Doc. 1], y durante él no hemos tenido ni procreado ningunos hijos, como asimismo declaro y declaré por mis bienes, los que constará a la dicha mi mujer, a 
quien asimismo le consta el estado de mis dependencias activas y pasivas. $Y$ para que se guarde, cumpla y ejecute este poder y el testamento que en su virtud se hiciere, dejo y nombro por mi albacea testamentaria, fideicomisaria y tenedora de bienes a la dicha doña Ursula Telles Girón, mi amada esposa, y le doy el poder y facultad que de derecho se requiere y es necesario, para que use de éste cargo según él, y cumplido y pagado en el remanente de cualesquier bienes, deudas y devechos y acciones que de cualquier manera me toquen y parezcan.

Dejo, instituyo y nombro por mi única y universal heredera a dicha doña Ursula, mi mujer, para lo que asi fuere, lo haya, goce y herede con la bendición de Dios nuestro Señor y la mia, en atención a no tener, como no tengo, herederos forzosos, ascendientes ni descendientes, que conforme a derecho me puedan ordenar heredar.

$Y$ por el presente, revoco y anulo, doy por de ninguin valor ni efecto otros cualesquier testamentos, codicilos, poderes para testar y otras últimas disposiciones, que antes de éste haya hecha por escrito, de palabra u en otra forma, para que no valgan ni hagan fe judicial, ni extrajudicialmente, salvo el presente testamento, que en virtud se hiciere, que quiero se guarde, cumpla y ejecute por mi ultima voluntad o para aquello que mejor en derecho lugar haya.

Que es hecho en la ciudad de México, en dos de abril de mil setecientos cuarenta y seis años. Y yo el escribano doy fe conozco al otorgante, que a lo que notoriamente parece está enfermo en cama, en su entero juicio, cumplida memoria y entendimiento natural, asi lo otorgó y no firmó por no poderlo hacer, hizolo a su ruego uno de sus testigos, siéndolo de este otorgamiento: Ambrosio de Ursuia, Santiago de Salazar, Josef Flores, Francisco Terán y Josef Contreras, vecinos de México.

A ruego y por testigo Josef de Contreras [ribrica]

\author{
Felipe Muñoz de Castro \\ [ribrica] \\ escribano real
}

A.N.cd.M., Not. Felipe Muñoz de Castro (391), Libro 2602, fs. 90v-91v. 